\title{
A new diagram of Earth's global energy budget
}

\author{
Miklos Zagoni ${ }^{1}$
}

Received: 26 November 2014/ Accepted: 23 July 2015/Published online: 19 August 2015

(C) Akadémiai Kiadó 2015

\begin{abstract}
A new global mean energy budget diagram is offered for discussion and further examination. The main motivation for creating this figure was the observation that a quasi-discrete flux quantity structure seems to appear behind the best published energy budget data. This structure underneath the observed global energy flow system might represent an idealized, hypothetic normal (steady) state onto which the actual climatic regimes and their changes can be projected. The unit of the all-sky structure is the value of the flux element called longwave cloud radiative effect (LWCRE), termed also the greenhouse effect of clouds; under prevailing average conditions, it turns out to be numerically equal to the all-sky surface transmitted irradiance, $\mathrm{S}_{\mathrm{T}}($ all). There is also a clear-sky structure, as reported in earlier studies, where the unit of measure is one $\mathrm{S}_{\mathrm{T}}$ (clear). Three important features are independent of the discrete units: (a) the energies at the surface are equal to the total energy at top-of-atmosphere plus one LWCRE; (b) the energies in the atmosphere are equal to the energy at the surface plus two LWCRE; (c) the shortwave ( $\mathrm{SW}$ ) radiation absorbed by the surface is equal to the longwave (LW) energy in the all-sky greenhouse effect. The aim of our study is to present the system as it reveals itself in the data; theoretical explanation is out of our recent scope.
\end{abstract}

Miklos Zagoni

miklos.zagoni@gmail.com; miklos.zagoni@t-online.hu

1 Eötvös Loránd University, Budapest, Hungary 


\section{Graphical Abstract}

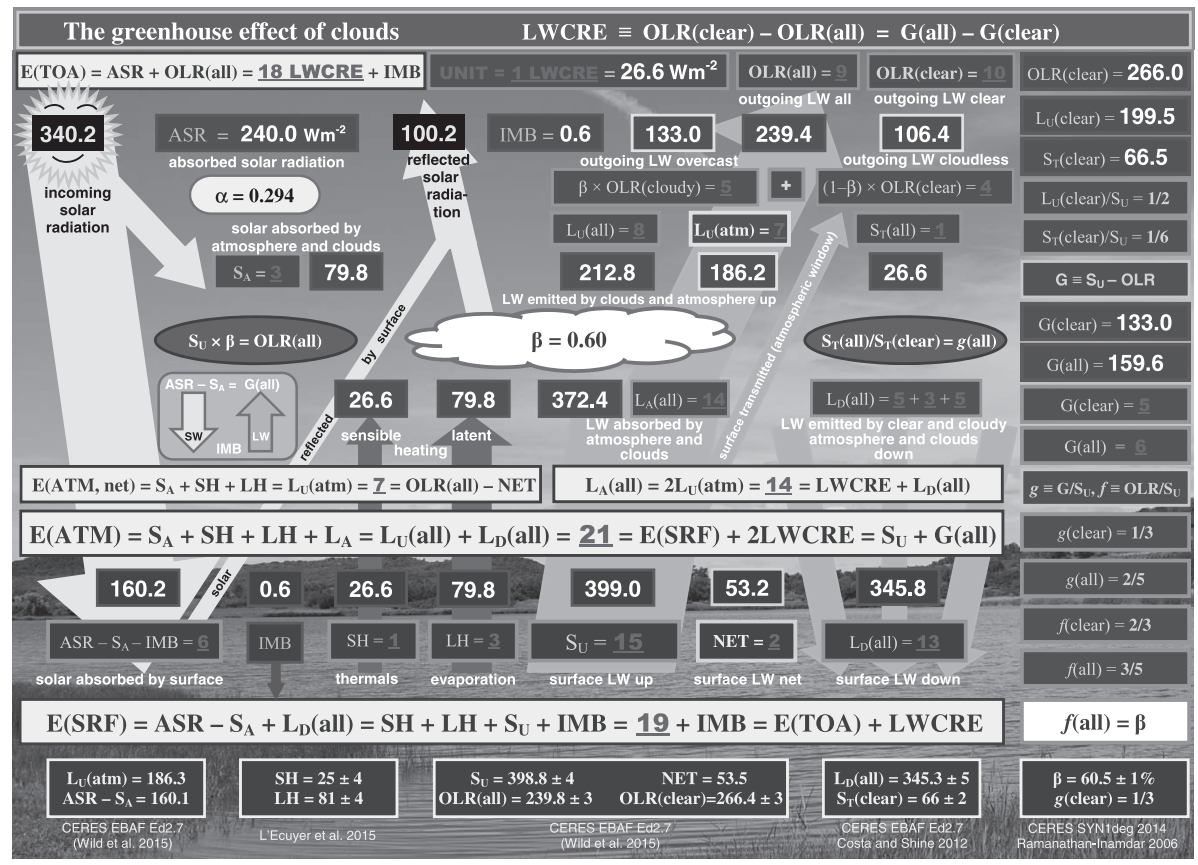

Keywords Earth's energy budget - Cloud radiative effect - Greenhouse effect of clouds . Energy balance equations
Abbreviations
ASR Absorbed (=incoming minus reflected) solar radiation
$\beta$
Cloud area fraction
CERES Clouds and the Earth's radiant energy system
EBAF Energy balanced and filled
$f \quad$ Transfer function, $f=\mathrm{OLR} / \mathrm{S}_{\mathrm{U}}$, also called planetary emissivity
$g \quad$ Greenhouse function, $g=\mathrm{G} / \mathrm{S}_{\mathrm{U}}=1-f$
$\mathrm{G} \quad$ Greenhouse effect, $\mathrm{G}=\mathrm{S}_{\mathrm{U}}-$ OLR
GEWEX Global energy and water exchanges project
ISCCP International satellite cloud climatology project
$\mathrm{L}_{\mathrm{A}} \quad$ Longwave radiation absorbed in the atmosphere
$\mathrm{L}_{\mathrm{D}} \quad$ Downward emitted atmospheric longwave radiation at the surface, also termed DLR or 'back-radiation'
$\mathrm{L}_{\mathrm{U}} \quad$ Upward emitted atmospheric longwave radiation at TOA, also termed 'thermal cooling to space'
LH Latent heat (evapotranspiration)
LWCRE Longwave cloud radiative effect
NET Surface net longwave radiative cooling, NET $=\mathrm{S}_{\mathrm{U}}-\mathrm{L}_{\mathrm{D}}$ (all)
OLR Outgoing longwave radiation
$\mathrm{S}_{\mathrm{A}} \quad$ Shortwave radiation absorbed in the atmosphere 


$\begin{array}{ll}\mathrm{SH} & \text { Sensible heat (thermals, convection) } \\ \mathrm{SRF} & \text { Surface } \\ \mathrm{S}_{\mathrm{T}} & \text { Surface transmitted irradiance } \\ \mathrm{S}_{\mathrm{U}} & \text { Surface upward longwave radiation } \\ \mathrm{T}_{\mathrm{A}} & \text { Longwave transmittance, } \mathrm{T}_{\mathrm{A}}=\mathrm{S}_{\mathrm{T}} / \mathrm{S}_{\mathrm{U}} \\ \mathrm{TOA} & \text { Top of the atmosphere }\end{array}$

\section{Introduction}

From the diagram of Kiehl and Trenberth (1997), reproduced in the third and fourth assessment reports of IPCC in 2001 and 2007, through its updates (Trenberth et al. 2009; Trenberth and Fasullo 2012) and alternatives (Stevens and Schwartz 2012; Stephens et al. 2012) to the most recently published energy balance estimates (Wild et al. 2013, 2015; NASA LaRC Energy Budget Poster 2014; L'Ecuyer et al. 2015; Stephens and L'Ecuyer 2015), there are two types of representations of the global energy budgets. The most informative descriptions give the detailed decomposition of OLR into its three different energy flow elements: emitted by atmosphere, atmospheric window, and cloud radiation; the latter quantity is longwave cloud radiative effect [LWCRE, defined as the reduction of outgoing longwave radiation in the presence of clouds, LWCRE = OLR(clear) - OLR(all), Coakley and Baldwin 1984; Ramanathan 1987; Stephens and Greenwald 1991], rather than the realistic cloud top radiation. A more simplified approach displays only some of the elements listed above: atmospheric window was quantified in Stevens and Schwartz (2012), atmospheric upward emission in L'Ecuyer et al. (2015) and in Stephens and L'Ecuyer (2015); but none of these elements was shown in the IPCC (2013) diagram.

In this study we try to create a complete picture with the most recent observed data. The burden of our approach is that our diagram might seem overcomplicated, but the advantage is that all information is available in one frame, which might help to quantify not only the primary elements in the global energy budget but the secondary (composite, derived) energy flow components such as ratios, internal proportions, clear-sky and all-sky values, and certain greenhouse effect relationships as well.

The novelty of our diagram is threefold. First, an internal structure is presented, where all the energy flow elements are located in a grid, occupying their position in a given, specific order. Second, we try to connect the values of some fluxes with the cloud area fraction, which is also displayed. Third, there are well-defined relationships among the topof-atmosphere (TOA), internal atmospheric (ATM) and surface (SRF) energy budgets, being valid independently of the lattice. Our graphic presents the whole structure in six different ways: we give the flux quantities (i) by their best observed value with estimated error bounds and the relevant data source of that flux element; (ii) by their proposed steady state (equilibrium) value; (iii) by their position in the structure expressed in integer units (the all-sky unit of measure is one LWCRE); (iv) by the relevant energy balance equations, describing definite connections between the surface, atmospheric and TOA energy contents; (v) by their specific whole number ratios and proportions; (vi) and by decomposing the outgoing longwave radiation and back-radiation (downward atmospheric LW emission) into their energy flow elements.

The numerical value of LWCRE in the structure, under equilibrium conditions, is equal to $\mathrm{S}_{\mathrm{T}}$ (all); see Fig. 1 and Table 1. There is also a clear-sky structure, where the fluxes are displayed in units of one $S_{\mathrm{T}}$ (clear), see Table 2 . 
Table 1 All-sky equilibrium structure with our proposed best values and balance equations

\begin{tabular}{lcc}
\hline Quantity & Unit: $1 \mathrm{~S}_{\mathrm{T}}$ (all) & Value $\left(\mathrm{W} \mathrm{m}^{-2}\right)$ \\
\hline LWCRE & 1 & 26.6 \\
NET [= $\mathrm{S}_{\mathrm{U}}-\mathrm{L}_{\mathrm{D}}$ (all)] & 2 & 53.2 \\
$\mathrm{~S}_{\mathrm{A}}$ (all) & 3 & 79.8 \\
$\mathrm{SH}+\mathrm{LH}$ & 4 & 106.4 \\
$\mathrm{G}$ (clear) & 5 & 133.0 \\
$\mathrm{G}($ all $)$ & 6 & 159.6 \\
$\mathrm{~L}_{\mathrm{U}}($ atm $)$ & 7 & 186.2 \\
$\mathrm{~L}_{\mathrm{U}}$ (all) & 8 & 212.8 \\
OLR(all) & 9 & 239.4 \\
OLR(clear) & 10 & 266.0 \\
$\mathrm{~L}_{\mathrm{D}}$ (atm) & 12 & 319.2 \\
$\mathrm{~L}_{\mathrm{D}}$ (all) & 13 & 345.8 \\
$\mathrm{~L}_{\mathrm{A}}$ (all) & 14 & 372.4 \\
$\mathrm{~S}_{\mathrm{U}}$ & 15 & 399.0 \\
\hline
\end{tabular}

Total energy at TOA: $\mathrm{E}(\mathrm{TOA})=\mathrm{ASR}+\mathrm{OLR}($ all $)$

Net atmospheric energy balance equation: $\mathrm{E}(\mathrm{ATM}, \mathrm{NET})=\mathrm{S}_{\mathrm{A}}($ all $)+\mathrm{LH}+\mathrm{SH}=\mathrm{L}_{\mathrm{U}}(\mathrm{atm})=$ OLR(all) - NET

$\mathrm{G}($ all $)=\mathrm{S}_{\mathrm{U}}-\mathrm{OLR}($ all $)=\mathrm{L}_{\mathrm{D}}($ all $)-\mathrm{L}_{\mathrm{U}}($ atm $)$

$\mathrm{G}($ clear $)=\mathrm{S}_{\mathrm{U}}-\mathrm{OLR}($ clear $)=\mathrm{L}_{\mathrm{D}}($ all $)-\mathrm{L}_{\mathrm{U}}($ all $)$

Gross atmospheric energy balance equation:

$\mathrm{E}(\mathrm{ATM})=\mathrm{S}_{\mathrm{A}}($ all $)+\mathrm{L}_{\mathrm{A}}($ all $)+\mathrm{SH}+\mathrm{LH}=\mathrm{L}_{\mathrm{D}}($ all $)+\mathrm{L}_{\mathrm{U}}($ all $)=\mathrm{ASR}+\mathrm{OLR}($ all $)+3 \mathrm{LWCRE}=\mathrm{S}_{\mathrm{U}}+$ $\mathrm{G}($ all $)=\mathbf{2 1}$ units of $\mathrm{S}_{\mathrm{T}}$ (all)

$\mathrm{E}(\mathrm{ATM})=\mathrm{E}(\mathrm{TOA})+\mathrm{G}(\mathrm{all}) / 2$

Surface balance equation:

$\mathrm{E}(\mathrm{SRF})=\mathrm{ASR}-\mathrm{S}_{\mathrm{A}}($ all $)+\mathrm{L}_{\mathrm{D}}($ all $)=\mathrm{SH}+\mathrm{LH}+\mathrm{S}_{\mathrm{U}}=\mathrm{ASR}+\mathrm{OLR}($ all $)+\mathrm{LWCRE}=\mathrm{E}(\mathrm{TOA})+$ LWCRE $=19$ units of $S_{T}$ (all)

$\mathrm{S}_{\mathrm{U}}=\mathrm{E}(\mathrm{TOA})-\mathrm{S}_{\mathrm{A}}($ all $)=2 \mathrm{~L}_{\mathrm{U}}($ atm $)+\mathrm{LWCRE}=2 \mathrm{~L}_{\mathrm{U}}($ all $)-\mathrm{LWCRE}$

\section{Data and relationships used in this study}

The primal dataset we use is CERES EBAF Ed2.7, as presented in Wild et al. (2015, esp. Table 3). Surface upward longwave radiation $\left(\mathrm{S}_{\mathrm{U}}\right)$ is $398.8 \mathrm{~W} \mathrm{~m}^{-2}$ there. For a 24-year (1984-2007) period the NASA LARC/GEWEX experiment (Stackhouse et al. 2011) has $\mathrm{S}_{\mathrm{U}}=396.4 \mathrm{~W} \mathrm{~m}^{-2}$. The latest IPCC assessment report (IPCC 2013) presents $398 \mathrm{~W} \mathrm{~m}^{-2}$ within the error bounds of [394, 400]; the data analysis of L'Ecuyer et al. (2015) and a second optimization of Stephens and L'Ecuyer (2015), after applying relevant energy balance constraints, propose $\mathrm{S}_{\mathrm{U}}=399 \mathrm{~W} \mathrm{~m}^{-2}$ within $\pm 5 \mathrm{~W} \mathrm{~m}^{-2}$ error margins. In our diagram we accept this mean value. (Quantities in bold typeset are the proposed elements of the idealized steady state where we do not indicate error bounds for them.)

Incoming solar radiation is $340.4 \mathrm{~W} \mathrm{~m}^{-2}$ in CERES EBAF, the reflected solar radiation from the surface is about $25 \mathrm{~W} \mathrm{~m}^{-2}$ and $75 \mathrm{~W} \mathrm{~m}^{-2}$ from the atmosphere and clouds. Trenberth and Fasullo (2012) and L'Ecuyer et al. (2015) have SW reflection altogether $102 \pm 2$; Stephens and L'Ecuyer (2015) give $100 \pm 4 \mathrm{~W} \mathrm{~m}^{-2}$. Absorbed solar radiation in the system in our study is set to be ASR $=\mathbf{2 4 0 . 0 ~} \mathrm{W} \mathrm{m}^{-2}$. The part of ASR being absorbed 
Table 2 Clear-sky equilibrium values and relationships

\begin{tabular}{llc}
\hline Quantity & Unit: $1 \mathrm{~S}_{\mathrm{T}}$ (clear) & Value $\left(\mathrm{W} \mathrm{m}^{-2}\right)$ \\
\hline $\mathrm{S}_{\mathrm{T}}$ (clear) & 1 & 66.5 \\
$\mathrm{G}$ (clear) & 2 & 133.0 \\
$\mathrm{~L}_{\mathrm{U}}$ (clear) & 3 & 199.5 \\
OLR(clear) & 4 & 266.0 \\
$\mathrm{~L}_{\mathrm{D}}$ (clear) & 5 & 332.5 \\
$\mathrm{~S}_{\mathrm{U}}$ & 6 & 399.0 \\
\hline
\end{tabular}

Source MM4 and M7

$\mathrm{S}_{\mathrm{U}}=3 \mathrm{OLR}($ clear $) / 2$

$\mathrm{S}_{\mathrm{U}}=2 \mathrm{~L}_{\mathrm{U}}$ (clear)

$\mathrm{S}_{\mathrm{T}}($ clear $)=\mathrm{S}_{\mathrm{U}} / 6$

$\mathrm{L}_{\mathrm{U}}($ clear $) / \mathrm{L}_{\mathrm{D}}($ clear $)=3 / 5$

$\mathrm{S}_{\mathrm{U}}-\mathrm{S}_{\mathrm{T}}($ clear $)=\mathrm{L}_{\mathrm{A}}($ clear $)=\mathrm{L}_{\mathrm{D}}($ clear $)$

$\mathrm{G}($ clear $)=\mathrm{OLR}($ clear $) / 2$

$\mathrm{L}_{\mathrm{D}}($ clear $)-\mathrm{L}_{\mathrm{U}}($ clear $)=\mathrm{G}($ clear $)$

$\mathrm{L}_{\mathrm{D}}($ clear $)+\mathrm{L}_{\mathrm{U}}($ clear $)=2 \mathrm{OLR}($ clear $)$

$\mathrm{S}_{\mathrm{A}}($ clear $)+(\mathrm{SH}+\mathrm{LH})($ clear $)=\mathrm{L}_{\mathrm{U}}($ clear $)$

$\mathrm{S}_{\mathrm{A}}($ clear $)=\mathrm{S}_{\mathrm{T}}($ clear $)$

$(\mathrm{SH}+\mathrm{LH})($ clear $)=\mathrm{G}($ clear $)$

in the atmosphere is $\mathrm{S}_{\mathrm{A}}=78.1 \mathrm{~W} \mathrm{~m}^{-2}$ in CERES EBAF; $79 \mathrm{~W} \mathrm{~m}^{-2}(74,91)$ in IPCC (2013); and $80 \mathrm{~W} \mathrm{~m}^{-2}$ within the same limits in the detailed land-ocean assessment of Wild et al. (2015). We accept the latter mean with a value of $S_{A}=79.8 \mathrm{~W} \mathrm{~m}^{-2}$. These together let the surface solar absorption ASR $-\mathrm{S}_{\mathrm{A}}=161 \mathrm{~W} \mathrm{~m}^{-2}$ in Trenberth and Fasullo (2012) and $160.1 \mathrm{~W} \mathrm{~m}^{-2}$ in Wild et al. (2015); we have ASR $-\mathrm{S}_{\mathrm{A}}=\mathbf{1 6 0 . 2}$ $\mathrm{W} \mathrm{m}{ }^{-2}$ in our model.

Outgoing longwave radiation under all-sky conditions in the CERES EBAF Ed2.7 is OLR(all) $=239.8 \mathrm{~W} \mathrm{~m}^{-2}$; the NASA/GEWEX product has OLR(all) $=237.8 \mathrm{~W} \mathrm{~m}^{-2}$ as a 24-year mean. In our diagram we calculate with the value of OLR(all) $=\mathbf{2 3 9 . 4} \mathrm{W} \mathrm{m}^{-2}$.

Trenberth et al. (2009) introduce an imbalance flux element at the surface for oceanic heat absorption with a value of $0.9 \mathrm{~W} \mathrm{~m}^{-2}$. Wild et al. (2015) provide $0.6 \pm 0.4 \mathrm{~W} \mathrm{~m}^{-2}$ for this term; Stephens and L'Ecuyer (2015) propose $0.45 \pm 0.4 \mathrm{~W} \mathrm{~m}^{-2}$. A recent study on Earth's net radiative imbalance says that IMB was $0.47 \pm 0.67 \mathrm{~W} \mathrm{~m}^{-2}$ during 1985-2012 (Allan et al. 2014). Hence, for equilibrium purposes, we might have properly chosen the zero mean value. Accepting ASR $=240.0 \mathrm{~W} \mathrm{~m}^{-2}$, an SW source of TOA and surface imbalance of $\mathrm{IMB}=\mathrm{ASR}-\mathrm{OLR}(\mathrm{all})=0.6 \mathrm{~W} \mathrm{~m}^{-2}$ is introduced into our graphic.

The clear-sky OLR in the most recent CERES EBAF TOA Ed2.8 is $265.6 \mathrm{~W} \mathrm{~m}^{-2}$; the diagram of Stephens et al. (2012), consistent with the earlier versions, gives $266.4 \pm 3.3 \mathrm{~W} \mathrm{~m}^{-2}$. In our structure it is presented as OLR(clear) $=\mathbf{2 6 6 . 0 ~} \mathrm{W} \mathrm{m}^{-2}$. For the longwave cloud effect, Stevens and Schwartz (2012) accept $26.5 \mathrm{~W} \mathrm{~m}^{-2}$; the diagram of Stephens et al. (2012) shows $26.6 \pm 5 \mathrm{~W} \mathrm{~m}^{-2}$ for the surface and $26.7 \pm 4 \mathrm{~W} \mathrm{~m}^{-2}$ at TOA; we use here LWCRE directly from its definition, given to one decimal figure, and have LWCRE $=$ OLR(clear) - OLR(all $)=26.6 \mathrm{~W} \mathrm{~m}^{-2}$. 
The components of OLR(all) obtained at TOA over cloudy and cloudless areas are described by Coakley and Baldwin (1984, Eq. 1), Charlock and Ramanathan (1985, Eq. 8), Stephens and Greenwald (1991) and Stevens and Schwartz (2012, Eq. 6) as:

$$
\operatorname{OLR}(\text { all })=\operatorname{OLR}(\text { cloudy }) \times \beta+\operatorname{OLR}(\text { clear }) \times(1-\beta)
$$

Here $\beta$ denotes cloud area fraction, and OLR(cloudy) is the emitted longwave irradiance at TOA obtained over the cloudy scenes; hence, from the known quantities, OLR(cloudy) $=[\mathrm{OLR}($ all $)-\operatorname{OLR}($ clear $) \times(1-\beta)] / \beta$.

Downward longwave radiation, $\mathrm{L}_{\mathrm{D}}$ (called also DLR or back-radiation) in CERES EBAF is $345.3 \mathrm{~W} \mathrm{~m}^{-2}$. The updated energy balance of Stephens et al. (2012) based on their earlier accurate assessments gives $345.6 \pm 9 \mathrm{~W} \mathrm{~m}^{-2}$. With our $\mathrm{S}_{\mathrm{U}}=399 \mathrm{~W} \mathrm{~m}^{-2}$ we accept $\mathrm{L}_{\mathrm{D}}($ all $)=\mathbf{3 4 5 . 8} \mathrm{W} \mathrm{m}^{-2}$; leaving a net surface longwave radiation, defined as $\mathrm{NET} \equiv \mathrm{S}_{\mathrm{U}}-\mathrm{L}_{\mathrm{D}}($ all $)=\mathbf{5 3 . 2} \mathrm{W} \mathrm{m}^{-2}$ (the CERES EBAF value is $398.8-345.3=$ $53.5 \mathrm{~W} \mathrm{~m}^{-2}$ ).

Latent heat $(\mathrm{LH})$ release by evaporation from the surface is $80 \mathrm{~W} \mathrm{~m}^{-2}$ in Trenberth and Fasullo (2012); in an update to the IPCC (2013) report, Wild et al. (2015) and Stephens and L'Ecuyer (2015) propose $\mathrm{LH}=82 \pm 7 \mathrm{~W} \mathrm{~m}^{-2}$; global hydrological cycle evaluations by L'Ecuyer et al. (2015) have $81 \pm 4 \mathrm{~W} \mathrm{~m}^{-2}$; Bengtsson (2014) suggests LH $=80 \mathrm{~W} \mathrm{~m}^{-2}$. In our diagram we accept the latter mean with $\mathrm{LH}=\mathbf{7 9 . 8} \mathrm{W} \mathrm{m}^{-2}$. Surface non-radiative cooling $(\mathrm{LH}+\mathrm{SH})$, according to Stevens and Schwartz (2012) and the data assessment of L'Ecuyer et al. (2015), is $106 \mathrm{~W} \mathrm{~m}^{-2}$; ECHAM6 results in $106.5 \mathrm{~W} \mathrm{~m}^{-2}$ (Stevens et al. 2013); we use $106.4 \mathrm{~W} \mathrm{~m}^{-2}$, hence surface sensible heat $(\mathrm{SH})$ in our work is set to $\mathrm{SH}=26.6 \mathrm{~W} \mathrm{~m}^{-2}$.

Surface transmitted irradiance $\left(S_{T}\right)$ was calculated by Costa and Shine (2012) by detailed radiative transfer computations on 3D climatologies for clear skies. They found the value of $S_{\mathrm{T}}$ (clear) $=66 \mathrm{~W} \mathrm{~m}^{-2}$. Using a cloud area fraction of $\beta=0.67$ for a time period of 1983-1994 from ISCCP (Rossow and Schiffer 1999), they propose $\mathrm{S}_{\mathrm{T}}($ all) $=$ $(1-\beta) \times 66=22 \mathrm{~W} \mathrm{~m}^{-2}$. A value for clear-sky $\mathrm{LW}$ transmittance, $\mathrm{T}_{\mathrm{A}}=\mathrm{S}_{\mathrm{T}}($ clear $) / \mathrm{S}_{\mathrm{U}}$ was presented by Miskolczi (2007, hereafter M7) as $\mathrm{T}_{\mathrm{A}}=1 / 6$, leading to $\mathrm{S}_{\mathrm{T}}($ clear $)=$ $66 \mathrm{~W} \mathrm{~m}^{-2}$ for $\mathrm{S}_{\mathrm{U}}=396 \mathrm{~W} \mathrm{~m}^{-2}$, or with $\mathrm{S}_{\mathrm{U}}=399 \mathrm{~W} \mathrm{~m}^{-2}$ to $\mathrm{S}_{\mathrm{T}}$ (clear) $=\mathbf{6 6 . 5} \mathrm{W} \mathrm{m}^{-2}$. In our assessment we utilize the latter quantity.

The cloud area fraction from the NASA CERES SYN1deg product over a period of time 2000-2007 is $\beta=0.615$; then it shows a decrease to an average of $\beta=0.605$ for the years 2008-2014. Using a rounded value of $\beta=\mathbf{0 . 6}$, we suppose an equilibrium $\mathrm{S}_{\mathrm{T}}($ all $)=(1-\beta) \times 66.5=\mathbf{2 6 . 6} \mathrm{W} \mathrm{m}^{-2}$ in our paper. Therefore, all-sky longwave absorption in the atmosphere, defined as $\mathrm{L}_{\mathrm{A}}$ (all) $\equiv \mathrm{S}_{\mathrm{U}}-\mathrm{S}_{\mathrm{T}}$ (all) is $\mathbf{3 7 2 . 4} \mathrm{W} \mathrm{m}^{-2}$. Trenberth and Fasullo (2012) have $374 \mathrm{~W} \mathrm{~m}^{-2}$ for this value. The clear-sky longwave atmospheric absorption is $\mathrm{L}_{\mathrm{A}}$ (clear) $\equiv \mathrm{S}_{\mathrm{U}}-\mathrm{S}_{\mathrm{T}}$ (clear) $=\mathbf{3 3 2 . 5} \mathrm{W} \mathrm{m}^{-2}$.

The cooling to space expression (Green 1967; Goody and Yung 1989) made possible to treat column infrared cooling rates separately from internal transfer processes. The corresponding global and spectral average balance equation, as given by Stephens et al. (1994, Eq. 9); Inamdar et al. (2004 see def. in their Table 1), or Allan (2006, Eq. 4) is as follows:

$$
\mathrm{LW} \text { Cooling }=\mathrm{S}_{\mathrm{U}}-\mathrm{OLR}-\mathrm{L}_{\mathrm{D}}=\mathrm{NET}-\mathrm{OLR}
$$

where NET, following Allan (2006, Eq. 1) is as defined above. Note that LW Cooling is negative here. Introducing longwave upward atmospheric emission as its opposite, $\mathrm{L}_{\mathrm{U}} \equiv-\mathrm{LW}$ Cooling, by simple re-arrangement, applying the greenhouse effect definition 
of Raval and Ramanathan (1989), we have another expression for the greenhouse effect (M7, Eqs. 5, 6):

$$
\mathrm{G} \equiv \mathrm{S}_{\mathrm{U}}-\mathrm{OLR}=\mathrm{L}_{\mathrm{D}}-\mathrm{L}_{\mathrm{U}}
$$

A direct arithmetic consequence is

$$
\mathrm{L}_{\mathrm{U}}=\mathrm{S}_{\mathrm{A}}+\mathrm{LH}+\mathrm{SH}
$$

These equations are exactly satisfied in the diagrams of L'Ecuyer et al. (2015), Stephens and L'Ecuyer (2015), and by the global average and CERES EBAF values in Table 3 of Wild et al. (2015). For a numerical quantity of $\mathrm{L}_{\mathrm{U}}$, Allan (2006) suggests a global mean of $\mathrm{L}_{\mathrm{U}}=183.5 \pm 5 \mathrm{~W} \mathrm{~m}^{-2}$ with $\mathrm{S}_{\mathrm{U}}=396 \mathrm{~W} \mathrm{~m}^{-2}$; Trenberth and Fasullo (2012) have $187 \mathrm{~W} \mathrm{~m}^{-2}$. The CERES EBAF product gives $186.3 \mathrm{~W} \mathrm{~m}^{-2}$ (Wild et al. 2015); we accept this latter value in our diagram as $\mathrm{L}_{\mathrm{U}}(\mathrm{atm})=\mathbf{1 8 6 . 2} \mathrm{W} \mathrm{m}^{-2}$; see Fig. 1. Note that several values in our structure differ only with $0.1 \mathrm{~W} \mathrm{~m}^{-2}$ from the best observed value.

\section{Results: the structure}

\subsection{Greenhouse effect and greenhouse factors}

The value of the all-sky and clear-sky greenhouse effect is $\mathrm{G}($ all $)=\mathrm{S}_{\mathrm{U}}-\mathrm{OLR}($ all) $=399-239.4=\mathbf{1 5 9 . 6} \mathrm{W} \mathrm{m}^{-2}$ and $\mathrm{G}($ clear $)=399-266=\mathbf{1 3 3} \mathrm{W} \mathrm{m}^{-2}$. Their difference is called the greenhouse effect of clouds: G(all) - G(clear) = LWCRE (Ramanathan et al. 1989). The normalized greenhouse factors, defined as $g($ all $) \equiv \mathrm{G}($ all $) / \mathrm{S}_{\mathrm{U}}$ and $g($ clear $) \equiv \mathrm{G}($ clear $) / \mathrm{S}_{\mathrm{U}}$ are $g($ all $)=\mathbf{0 . 4}$ and $g($ clear $)=\mathbf{1 / 3}$. The corresponding transfer functions, called also planetary emissivity (Bengtsson 2012) are $f($ all) $\equiv$ OLR $($ all $) / \mathrm{S}_{\mathrm{U}}=1-g($ all $)$, and $f($ clear $) \equiv \mathrm{OLR}($ clear $) / \mathrm{S}_{\mathrm{U}}=1-g($ clear $)$. With the NASA/ GEWEX data, the measured value of $f$ (all) is $237.8 / 396.4=0.5999$. With the equilibrium quantities: $f($ all $)=\mathbf{0 . 6}$ and $f($ clear $)=\mathbf{2 / 3}$. The $g($ clear $)=1 / 3$ relationship was noted by Ramanathan and Inamdar (2006), and is equivalent to G(clear) = OLR(clear)/2 or $\mathrm{S}_{\mathrm{U}}=3 \mathrm{OLR}$ (clear) $/ 2$ or $\mathrm{S}_{\mathrm{U}}=3 \mathrm{G}$ (clear). These ratios in the given numerical form were first described by M7.

\section{2 $\mathrm{L}_{\mathrm{U}}($ clear $)$}

In the clear-sky subset, outgoing thermal radiation is a sum of two components: OLR (clear) $=\mathrm{S}_{\mathrm{T}}$ (clear) $+\mathrm{L}_{\mathrm{U}}$ (clear); having OLR(clear) $=266 \mathrm{~W} \mathrm{~m}^{-2}$ and $\mathrm{S}_{\mathrm{T}}$ (clear) $=66.5 \mathrm{~W} \mathrm{~m}^{-2}$, this leads to $\mathrm{L}_{\mathrm{U}}$ (clear) $=199.5 \mathrm{~W} \mathrm{~m}^{-2}$. This value is the half of $\mathrm{S}_{\mathrm{U}}=399 \mathrm{~W} \mathrm{~m}^{-2}$. The relationship $\mathrm{S}_{\mathrm{U}}=2 \mathrm{~L}_{\mathrm{U}}$ (clear) was first described by Miskolczi and Mlynczak (2004, hereafter MM4) as a result of their computations.

\section{$3.3 \mathrm{~S}_{\mathbf{T}}($ all $)$}

Let us now realize that

$$
\mathrm{S}_{\mathrm{T}}(\text { all })=\mathrm{LWCRE}
$$

in the equilibrium set of quantities, both having a value of $26.6 \mathrm{~W} \mathrm{~m}^{-2}$. This equality was first noticed by M7: "the LW effect of the cloud cover is equal to closing the IR 


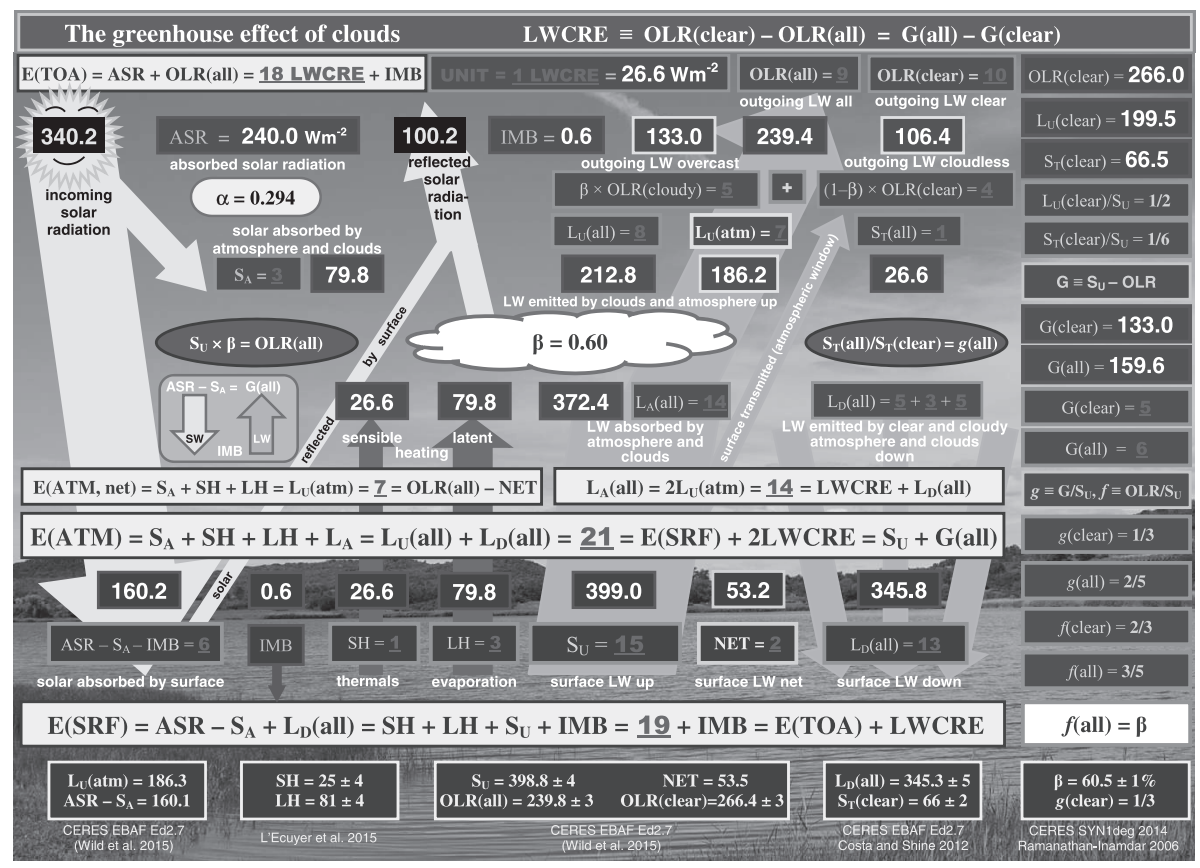

Fig. 1 Global mean energy budget and the greenhouse effect of clouds. Discrete quantities are in units of one LWCRE; the quantity for OLR(all) $=239.8 \mathrm{~W} \mathrm{~m}^{-2}$ of CERES EBAF v2.7 (see Wild et al. 2015) is $\mathrm{LWCRE}=26.64 \mathrm{~W} \mathrm{~m}^{-2}$; we display the structure to one decimal figure. The net atmospheric energy balance equation is from the cooling-to-space approximation; $\mathrm{L}_{\mathrm{U}}(\mathrm{atm})=7$ units $=186.2 \mathrm{~W} \mathrm{~m}^{-2}$. $\mathrm{L}_{\mathrm{U}}($ all $)$ is the total atmospheric and cloudy contribution to OLR(all). The outgoing radiation over cloudy areas is OLR(cloudy); its contribution to OLR(all) is $\beta \times$ OLR(cloudy). The clear-sky contribution to OLR(all) is $(1-\beta) \times$ OLR(clear). The values of $\mathrm{L}_{\mathrm{U}}$ (clear), $\mathrm{S}_{\mathrm{T}}$ (clear), $f, g$, their relationships, and $\mathrm{S}_{\mathrm{T}}($ all $)=\mathrm{LWCRE}$ are from M7. Best observed and computed values with their estimated error margins and some data sources are also shown in the bottom rows of the diagram. Fluxes are in $\mathrm{W} \mathrm{m}^{-2} ; g, f$ and $\beta$ are dimensionless

atmospheric window". A possible physical explanation is that the surface transmitted longwave energy being lost in the atmospheric window is gained back by the cloud greenhouse effect.

A direct consequence: the total ('up plus down') longwave cloud effect (LWCRE at TOA + LWCRE at the surface), equals to the surface net LW radiation: NET $\equiv$ $S_{U}-L_{D}($ all $)=2$ LWCRE (see for example Stephens et al. 2012). This equality is numerically justified, and expressed in the fundamental relationship that the energies in the atmospheric budget equal to the energies at the surface plus the double of the greenhouse effect of clouds:

$$
\mathrm{E}(\mathrm{ATM})=\mathrm{E}(\mathrm{SRF})+2 \mathrm{LWCRE}
$$

Notice that LWCRE $=$ OLR(clear) $/ 10$ in the data, therefore, from G(clear) $=$ OLR(clear)/ 2 , we have $\mathrm{G}$ (clear) $=5 \mathrm{LWCRE}$ and $\mathrm{G}($ all $)=6 \mathrm{LWCRE}$; further, $\beta \times$ OLR(cloudy) $=$ $\mathrm{G}$ (clear) in the matrix. Involving $S_{U}$ from the definition of $S_{U}=$ OLR(all) + $\mathrm{G}($ all $)=\mathrm{OLR}($ clear $)+\mathrm{G}$ (clear), we can immediately obtain $\mathrm{S}_{\mathrm{U}}=15$ LWCRE.

The system determines the necessary place of the remaining energy flow components as well: atmospheric solar absorption: $\mathrm{S}_{\mathrm{A}}=3 \mathrm{LWCRE}$; the downwelling radiation at the 
surface, ASR $-\mathrm{S}_{\mathrm{A}}+\mathrm{L}_{\mathrm{D}}($ all $)-\mathrm{S}_{\mathrm{U}}$, is balanced by the sensible and latent heat transfer, $\mathrm{SH}+\mathrm{LH}=106.4 \mathrm{~W} \mathrm{~m}^{-2}$ (being equal to $4 \mathrm{LWCRE}$ ); from where $\mathrm{SH}=1 \mathrm{LWCRE}$ and $\mathrm{LH}=3 \mathrm{LWCRE}$ in the pattern, with the important relationships of $\mathrm{SH}+\mathrm{LH}+$ $\mathrm{LWCRE}=\mathrm{G}$ (clear) and $\mathrm{SH}+\mathrm{LH}+\mathrm{NET}=\mathrm{G}($ all $)$.

Now we have arrived at the following expression, showing the relationship between the equilibrium values of OLR(all), cloud cover fraction and $S_{U}$ as OLR(all) $=S_{U} \times \beta$. It is straightforward from here that $\mathrm{G}($ all $)=\mathrm{S}_{\mathrm{U}} \times(1-\beta)=\mathrm{ASR}-\mathrm{S}_{\mathrm{A}}$ in the equilibrium pattern.

This point allows us to formally decompose $\mathrm{L}_{\mathrm{D}}$ (all) into the following three energy flow elements as

$$
\begin{aligned}
\mathrm{L}_{\mathrm{D}}(\text { all }) & =\beta \times \mathrm{OLR}(\text { cloudy })+\beta \times \mathrm{G}(\text { clear })+(1-\beta) \times \mathrm{L}_{\mathrm{D}}(\text { clear }) \\
& =\mathrm{G}(\text { clear })+\beta \times \mathrm{G}(\text { clear })+\mathrm{G}(\text { clear })=13 \mathrm{LWCRE}
\end{aligned}
$$

Our final formula in the framework, under the steady-state conditions of $\beta=0.6$ and $\operatorname{OLR}($ all $) / \mathrm{S}_{\mathrm{U}}=3 / 5$, connects planetary emissivity (all-sky transfer function) to the cloud cover fraction as

$$
f(\text { all })=\beta
$$

Note that the value of $\beta=0.6$ in these relationships assumes that the cloud layer is completely opaque in the infrared. If not (as for example, in realistic cirrus clouds), a higher area fraction is possible. This might be an explanation why the observed CERES cloud area fraction is higher by about $0.5 \%$ than the equilibrium requirement of $\beta=0.6$.

The whole structure in units of one $\mathrm{LWCRE}=\mathrm{S}_{\mathrm{T}}($ all $)$ is shown in Table 1 . The clearsky subset is valid independently, as shown in Table 2, in units of one $\mathrm{S}_{\mathrm{T}}$ (clear); source: M7. The cloudy decomposition depends on $\beta=0.6$.

\section{Discussion}

The question may arise, is the Earth's radiation budget constrained? Our study suggests yes, there is a strict constraint, operating by the available absorbed energy, through the greenhouse effect of clouds. The 'how' is a theoretical problem, far beyond the scope of our present work where we simply describe the numbers and ratios as they reveal themselves in the data. But it must be noted that the unique global average state can be implemented through several regional and vertical temperature fields and precipitation distributions. Climatic regime fluctuations, and shifts, might happen through possible reorganisations of the cloud cover, cloud type and height, if atmospheric composition changes. Hemispheric and seasonal dislocation of insolation may well lead to global climate change, under one and the same global average greenhouse function value. Hence, our study says nothing about the equilibrium climate sensitivity; it only suggests that the equilibrium greenhouse sensitivity is zero.

Why does the system prefer a unique discrete state rather than using continuous flux variables? Internal symmetries might help to maintain the overall stability of the structure. For example, the equality

$$
\operatorname{OLR}(\text { all })=\mathrm{S}_{\mathrm{U}} \times \beta
$$

means that the cloud-covered part of the surface radiates the amount of OLR(all), while the cloudless part of the surface emits the remaining $\mathrm{G}($ all). Also, 


$$
\operatorname{OLR}(\text { all })=\mathrm{S}_{\mathrm{U}}-\beta \times \mathrm{OLR}(\text { clear })
$$

leads to $\beta \times \mathrm{OLR}$ (clear) $=\mathrm{G}($ all), representing a cross-determination between the clear and the cloudy atmospheric portions. Further inter-dependence is shown in

$$
\operatorname{OLR}(\text { all })=\mathrm{G}(\text { clear })+(1-\beta) \times \operatorname{OLR}(\text { clear })
$$

that is, OLR(all) can be symmetrically decomposed to $\operatorname{OLR}($ all $)=\mathrm{G}($ clear $)$ - LWCRE + G(clear).

This compilation

$$
\mathrm{OLR}(\text { all })=\mathrm{G}(\text { all })+\beta \times \mathrm{G}(\text { clear })
$$

describes again a cross-determination, as

$$
\operatorname{OLR}(\text { all })=\beta \times \mathrm{G}(\text { clear })+(1-\beta) \times \mathrm{S}_{\mathrm{U}}
$$

At the bottom of the atmosphere, the surface has two energy incomes, solar absorption and longwave back-radiation. Now it turns out that the shortwave energy absorbed by the surface covers entirely the energy of the all-sky greenhouse effect:

$$
\mathrm{ASR}-\mathrm{S}_{\mathrm{A}}=\mathrm{G}(\text { all })
$$

The principal relationship is that the energy flows at the surface are equal to the total (incoming plus outgoing) energy flows at TOA plus the greenhouse effect of clouds:

$$
\mathrm{E}(\mathrm{SRF})=\mathrm{E}(\mathrm{TOA})+\mathrm{LWCRE}
$$

The validity of Eq. (10) and (11) does not depend on the lattice structure but exhibits very general determinations.

Note that CERES EBAF Ed2.7 gives OLR(all) $=239.8 \mathrm{~W} \mathrm{~m}^{-2}$ and $\mathrm{S}_{\mathrm{U}}=398.8 \mathrm{~W} \mathrm{~m}^{-2}$ (Wild et al. 2015, Table 3), while the equilibrium surface radiation corresponding to this OLR would be $S_{U}=399.67 \mathrm{~W} \mathrm{~m}^{-2}$. If everything else remains unaltered, a further $0.16 \mathrm{~K}$ global surface warming is needed to reach the equilibrium.

The challenge ahead is to examine, what sort of physical principles, material conditions and dynamic processes are able to keep the observed ratios fixed under continuously changing atmospheric greenhouse gas concentrations.

\section{Summary}

A set of discrete parameters reveals itself in the data, far within to the uncertainties of observations, in some cases exactly at the best observed values, fitting into a particular 'quantized' pattern and satisfying specific whole number proportions and relationships. The clear-sky unit of measure is $\mathrm{S}_{\mathrm{T}}$ (clear) $=\mathrm{S}_{\mathrm{U}} / 6=66.5 \mathrm{~W} \mathrm{~m}^{-2}$; the corresponding relations were first presented in MM4 and M7. The all-sky unit is LWCRE $=26.6 \mathrm{~W} \mathrm{~m}^{-2}$. If the effective cloud area fraction is $\beta=0.6$ (and it is very close to it in the observations), LWCRE equals to $S_{\mathrm{T}}$ (all). The shortwave part, as well as the balance equations, fit into the structure on their own. The flux decomposition of OLR(all) and $\mathrm{L}_{\mathrm{D}}$ (all) depend on the value of $\beta$. There are relationships that are not depending on the whole number structure: surface energy is equal to the total energy at TOA plus LWCRE, and the atmospheric energy content is equal to the surface energies plus 2 LWCRE; further, the shortwave energy absorbed by the surface equals to the longwave energy content of the all-sky 
greenhouse effect. These relationships indicate that the distribution of energy in the system is not a free variable of the atmospheric greenhouse gas composition but predetermined by the boundary conditions. Physical explanation and theoretical interpretation require further research.

Acknowledgments This work was partly supported by the Hungarian Academy of Sciences, contract No. 17/2010, 29.543/2010. The Geodetic and Geophysical Research Institute, Sopron, is highly appreciated for adopting this project.

\section{References}

Allan R (2006) Variability in clear-sky longwave radiative cooling of the atmosphere. J Geophys Res 111:D22105. doi:10.1029/2006JD007304

Allan R, Liu C, Loeb N, Palmer M, Roberts M, Smith D, Vidale P-L (2014) Changes in global net radiative imbalance 1985-2012. Geophys Res Lett 41(15):5588-5597. doi:10.1002/2014GL060962

Bengtsson L (2012) Foreword: International Space Science Institute (ISSI) workshop on observing and modeling earth's energy flows. Surv Geophys 33:333-336. doi:10.1007/s10712-012-9194-y

Bengtsson L (2014) Foreword: International Space Science Institute (ISSI) workshop on the earth's hydrological cycle. Surv Geophys 35:485-488. doi:10.1007/s10712-013-9265-8

Charlock TP, Ramanathan V (1985) The albedo field and cloud radiative forcing produced by a general circulation model with internally generated cloud optics. J Atmos Sci 42:1408-1429

Coakley JA, Baldwin DG (1984) Towards the objective analysis of clouds from satellite imagery data. J Clim Appl Meteorol 23:1065-1099

Costa S, Shine K (2012) Outgoing longwave radiation due to directly transmitted surface emission. J Atmos Sci 69:1865-1870. doi:10.1175/JAS-D-11-0248.1

Goody RM, Yung YL (1989) Atmospheric radiation: theoretical basis, 2nd edn. Oxford University Press, New York

Green JSA (1967) Division of radiative streams into internal transfer and cooling to space. Q J R Meteorol Soc 93:371-372

Hartmann DL, Tank AMGK, Rusticucci M, Alexander LV, Brönnimann S, Charabi Y, Dentener FJ, Dlugokencky EJ, Easterling DR, Kaplan A, Soden BJ, Thorne PW, Wild M, Zhai PM, IPCC (2013) Observations: atmosphere and surface. In: Stocker TF, Qin D, Plattner G-K, Tignor M, Allen SK, Boschung J, Nauels A, Xia Y, Bex V, Midgley PM (eds) Climate change 2013: the physical science basis. Contribution of Working Group I to the Fifth Assessment Report of the Intergovernmental Panel on Climate Change. Cambridge University Press, Cambridge

Inamdar A, Ramanathan V, Loeb N (2004) Satellite observations of the water vapor greenhouse effect and column longwave cooling rates. J Geophys Res 109:D06104. doi:10.1029/2003JD003980

Kiehl J, Trenberth K (1997) Earth's annual global mean energy budget. Bull Am Meteorol Soc 78:197-208

L'Ecuyer T et al (2015) The observed state of the energy budget in the early 21st century. J Clim. doi:10. 1175/JCLI-D-14-00556.1

Miskolczi F (2007) Greenhouse effect in semi-transparent planetary atmospheres. Idojaras Q J Hung Meteorol Serv 111:1-40. http://owww.met.hu/idojaras/IDOJARAS_vol111_No1_01.pdf

Miskolczi F, Mlynczak M (2004) The greenhouse effect and the spectral decomposition of the clear-sky terrestrial radiation. Idojaras Q J Hung Meteorol Serv 108:209-251. http://owww.met.hu/idojaras/ IDOJARAS_vol108_No4_01.pdf

NASA (2014) NASA Langley Research Center energy budget poster, 26 June 2014 edition. http://scienceedu.larc.nasa.gov/energy_budget/pdf/ERB_Litho_v2014.06.26.pdf

Ramanathan V (1987) The role of earth radiation budget studies in climate and general circulation research. J Geophys Res Atmos 92:4075-4095

Ramanathan V, Inamdar A (2006) The radiative forcing due to clouds and water vapor. In: Kiehl JT, Ramanathan V (eds) Frontiers of climate modeling. Cambridge University Press, Cambridge (chapter 5)

Ramanathan V, Cess RD, Harrison EF, Minnis P, Barkstrom BR, Ahmad E, Hartmann D (1989) Cloud radiative forcing and climate: results from the Earth Radiation Budget Experiment. Science 243:57-63

Raval A, Ramanathan V (1989) Observational determination of the greenhouse effect. Nature 342:758-761

Rossow W, Schiffer A (1999) Advances in understanding clouds from ISCCP. Bull Am Meteorol Soc $80: 2261-2287$ 
Stackhouse PW Jr, Gupta SK, Cox SJ, Zhang T, Mikovitz JC, Hinkelman LM (2011) The NASA/GEWEX surface radiation budget release 3.0, 24.5-year dataset. GEWEX News 21(1):10-12

Stephens G, Greenwald T (1991) The Earth's radiation budget and its relation to atmospheric hydrology 2. Observation of cloud effects. J Geophys Res 96:15325-15340

Stephens G, L'Ecuyer T (2015) The Earth's energy balance. J Atmos Res. doi:10.1016/j.atmosres.2015.06. 024

Stephens GL, Slingo A, Webb M, Minnett P, Daum P, Kleinman L, Wittmeyer I, Randall D (1994) Observations of the Earth's Radiation Budget in relation to atmospheric hydrology. Part IV: atmospheric column radiative cooling over the world's oceans. J Geophys Res 99(D9):18585-18604

Stephens GL, Li J, Wild M, Clayson C, Loeb N, Kato S, L'Ecuyer T, Stackhouse W, Lebsock M, Andrews T (2012) An update on Earth's energy balance in light of the latest observations. Nat Geosci 5:691-696. doi:10.1038/ngeo1580

Stevens B, Schwartz SE (2012) Observing and modeling Earth's energy flows. Surv Geophys 33:779-816. doi:10.1007/s10712-012-9184-0

Stevens B et al. (2013) Atmospheric component of the MPI-M earth system model: ECHAM6. J Adv Model Earth Syst 5(2):146-172. doi:10.1002/jame.20015

Trenberth K, Fasullo J (2012) Tracking Earth's energy: from El Nino to global warming. Surv Geophys 33:413-426. doi:10.1007/s10712-011-9150-2

Trenberth K, Fasullo J, Kiehl J (2009) Earth's global energy budget. Bull Am Meteorol Soc 90:311-323

Wild M, Folini D, Schär C, Loeb N, Dutton E, König-Langlo G (2013) The global energy balance from a surface perspective. Clim Dyn 40:3107-3134. doi:10.1007/s00382-012-1569-8

Wild M, Folini D, Hakuba M, Schär C, Seneviratne S, Kato S, Rutan D, Ammann C, Wood E, König-Langlo G (2015) The energy balance over land and oceans: an assessment based on direct observations and CMIP5 climate models. Clim Dyn 44:3393-3429. doi:10.1007/s00382-014-2430-z 